\title{
Acute postoperative seizures following anterior temporal lobectomy for intractable partial epilepsy
}

\author{
Bhaskara Rao Malla, M.B., B.S., Terence J. O'Brien, M.B., B.S., F.R.A.C.P., Gregory D. Cascino, \\ M.D., Elson L. So, M.D, Kurupath Radhakrishnan, M.B., B.S., Peter Silbert, M.B., B.S., \\ F.R.A.C.P., and W. Richard Marsh, M.D.
}

Departments of Neurosurgery and Neurology, Mayo Clinic and Mayo Foundation, Rochester, Minnesota

Recurrence of seizures immediately following epilepsy surgery can be emotionally devastating, and raises concerns about the chances of successfully attaining long-term seizure control. The goals of this study were to investigate the frequency of acute postoperative seizure (APOS) occurring in the 1st postoperative week following anterior temporal lobectomy (ATL) to identify potential risk factors and to determine their prognostic significance.

One hundred sixty consecutive patients who underwent an ATL for intractable nonlesional temporal lobe epilepsy were retrospectively studied. Acute postoperative seizures occurred in 32 patients (20\%). None of the following factors were shown to be significantly associated with the occurrence of APOS: age at surgery, duration of epilepsy, side of surgery, extent of neocortical resection, electrocorticography findings, presence of mesial temporal sclerosis, and hippocampal volume measurements $(\mathrm{p}>0.05)$. Patients who suffered from APOS overall had a lower rate of favorable outcome with respect to seizure control at the last follow-up examination than patients without APOS (62.5\% compared with 83.6\%, p < 0.05). The type of APOS was of prognostic importance, with patients whose APOS were similar to their preoperative habitual seizures having a significantly worse outcome than those whose APOS were auras or were focal motor and/or generalized tonic-clonic seizures (excellent outcome: $14.3 \%, 77.8 \%$, and $75 \%$, respectively, $\mathrm{p}<0.05)$. Only patients who had APOS similar to preoperative habitual seizures were less likely to have an excellent outcome than patients without APOS $(14.3 \%$ compared with $75 \%, \mathrm{p}<$ 0.05). Timing of the APOS and identification of a precipitating factor were of no prognostic importance.

The findings of this study may be useful in counseling patients who suffer from APOS following ATL for temporal lobe epilepsy.

Key Words * temporal lobe epilepsy * temporal lobe seizure * epilepsy surgery * anterior temporal lobectomy * postoperative seizure

Acute postoperative seizures (APOS) following resective surgery for intractable partial epilepsy are seizures that occur during the 1st week after the operation.[10] Although APOS can occur after any type 
of craniotomy, the recurrence of seizures immediately following epilepsy surgery is particularly emotionally devastating to both patients and their families, and this understandably raises fears about the likelihood of successful long-term seizure control. Often it has been stated that APOS, particularly those that occur in the setting of a perioperative precipitating factor, such as subtherapeutic antiepileptic drug levels, do not reduce the likelihood of long-term seizure control.[9-11,26] On the other hand, authors of some studies have reported that APOS, particularly those that are similar to the patient's habitual preoperative seizures, indicate a poor prognosis similar to that of seizure recurrence later in the 1st postoperative year.[3,21,29] To date, there are few studies in which the importance of APOS has specifically been addressed. Many studies in which outcome of epilepsy surgery has been examined have excluded postoperative seizures that occurred before discharge from the hospital.[24] Most studies in which APOS have been evaluated involved heterogeneous groups of patients, including both patients who underwent temporal and extratemporal surgeries and/or patients with various types of pathological conditions. $[3,17,32]$

Here we report the results of a study of APOS in a group of consecutively treated patients who underwent an anterior temporal lobectomy (ATL) for nonlesional temporal lobe epilepsy. The aims of this study were to determine the incidence of APOS, to identify risk factors for their occurrence, to determine whether they signify a worse prognosis for long-term seizure control, and to determine whether the type of APOS, the timing of the APOS, or the presence of a precipitating factor has prognostic significance.

\section{CLINICAL MATERIAL AND METHODS}

\section{Patient Population}

One hundred sixty consecutive patients (77 male and 83 female) with intractable temporal lobe epilepsy who underwent an ATL and amygdalohippocampectomy at the Mayo Clinic, Rochester, Minnesota between 1988 and 1993 were included in the study. The mean age of the patients at the time of surgery was 32.4 years (range 8-57 years). Five additional patients who underwent selective amygdalohippocampectomy for temporal lobe epilepsy during this time period were excluded so that the incidence and prognostic significance of the APOS could be studied in a homogeneous group of patients. A selective amygdalohippocampectomy may potentially be associated with a different risk for acute or long-term postoperative seizures than a standard ATL and, therefore, bias the results of the study. A retrospective chart review was performed to extract patients' demographic details; potential preoperative risk factors (age at surgery, gender, duration of epilepsy prior to surgery, presence or absence of hippocampal atrophy on visual magnetic resonance [MR] imaging analysis, and hippocampal volume measurements); potential intraoperative risk factors (side of surgery, extent of lateral neocortical resection, presence or absence of neocortical spikes on the pre- or postresection electrocorticogram, and presence or absence of pathological findings in the resected specimen), and potential postoperative risk factors (subtherapeutic antiepileptic drug levels, intracranial infection, intracranial hemorrhage, metabolic disturbance, or other significant postoperative complications). Postsurgical outcome with respect to seizures was assessed by retrospective chart review according to a modified Engel scale[10] as follows: Class I was assigned to patients who were free of seizures, had auras only, or experienced a single seizure associated with discontinuation of medication; Class II to patients who had less than three seizures per year and more than 95\% reduction in seizure activity; Class III to patients who had 80 to $94 \%$ reduction in seizure activity; and Class IV to patients with less than $80 \%$ reduction in seizure activity. The group of patients with a Class I outcome was considered as having an excellent outcome, 
and the group combining patients with a Class I or II outcome was considered as having a favorable outcome. Outcome was assessed at 3 months and 1 year after surgery and at the last follow-up examination. All patients had a minimum of 12 months of postoperative follow-up review.

\section{Methods of MR Imaging}

Magnetic resonance imaging was performed using a 1.5-tesla scanner (Signa; GE Medical Systems, Milwaukee, WI) according to a standardized seizure protocol described by Jack.[18] This protocol included a spin-echo $\mathrm{T}_{1}$-weighted "whole-brain" volumetric series consisting of 124 contiguous slices at 1.6-mm thickness acquired perpendicular to the long axis of the hippocampal formation. The voxel dimensions were $0.875 \times 0.875 \times 1.6 \mathrm{~mm}$. The presence or absence of hippocampal atrophy was determined preoperatively by visual analysis of the MR images. Hippocampal volumes were measured by manual tracing as previously described,[5,19] as part of another ongoing study, by an operator who had no knowledge of APOS occurrence or surgical outcome.

\section{Surgical Methods}

Surgery in all patients was performed after general anesthesia had been induced. A standardized medial temporal resection of the amygdala, hippocampus, and parahippocampal gyrus was performed, along with a tailored lateral cortical resection. The amount of lateral cortex resected varied among patients, depending particularly on the results of the electrocorticography and the side of language dominance. In addition, the surgeon generally elected to carry the lateral temporal resection no farther than a prominent vein or arteries if present. The method and the relationship of electrocorticography to quantitative MR imaging and to operative outcome were analyzed and reported in detail in a previous publication.[6]

\section{Acute Postoperative Seizures}

Acute postoperative seizures were defined as any seizures (including auras) that occurred in the 1st week after surgery. Patients identified as having experienced APOS were divided into those who suffered from APOS exclusively in the first 24 hours after surgery (early APOS) and those in whom any seizure occurred from Day 2 to Day 7 postsurgery, even if there were also seizures on the 1st postoperative day (late APOS). Patients with APOS were also classified according to the type of seizure they experienced: seizures that were similar to preoperative habitual seizures, those typical of preoperative auras, and those that were focal motor seizures (FMS) and/or generalized tonic-clonic seizures (GTCS) only. Patients with APOS were also divided into those with and those without identifiable precipitating factors for the APOS (for example, subtherapeutic antiepileptic drug blood levels).

The rate of APOS was compared according to the following potential risk factors: side of surgery, presence of hippocampal atrophy on MR imaging, findings on pre- and postresection electrocorticograms, and pathological status of the resected specimen. Patients with APOS were compared with those without APOS according to age at surgery, gender, duration of epilepsy prior to surgery, hippocampal volume measurements (absolute volumes and side-to-side ratios), and extent of lateral neocortical resection. Outcome with respect to seizures was compared between patients with and patients without APOS. A comparison was also made between the various APOS subgroups based on the timing, type, and presence of potential precipitating factors.

\section{Statistical Analysis}

Fisher's exact test (two-tailed) was used to compare dichotomous variables (rates of APOS in patients 
with and without potential risk factors, proportions of patients with APOS who had excellent or favorable outcome compared with patients without APOS). The chi-square test was used when three or more variables were compared (types of APOS). The two-tailed nonpaired Student t-test was used to compare hippocampal volume measurements between patients with and patients without APOS.

\section{RESULTS}

\section{Patient Demographics}

The mean preoperative duration of epilepsy in the 160 patients was 23.4 years (range 2-55 years) and the mean duration of follow-up review was 37.4 months (range 12-94 months). Thirty-two patients (20\%) suffered from APOS. Fifteen experienced early and 17 patients late APOS.

\section{Type of APOS}

Seven patients suffered from APOS that were similar to their preoperative habitual seizures, nine had recurrence of their typical preoperative auras, and 16 had only FMS and/or GTCS. One of the patients who had recurrent habitual seizures and three of the patients with recurrent auras also had FMS or GTCS.

\section{Potential Risk Factors}

The rates of APOS distribution according to potential risk factors are listed in Table 1. There was no significant difference in rates of APOS with respect to side of surgery, presence or absence of hippocampal atrophy, presence or absence of spikes on the pre- or postresection electrocorticogram, or presence or absence of pathological characteristics in the resected specimen. No significant difference was found between patients who had APOS and those who did not with regard to age at surgery, gender, duration of epilepsy prior to surgery, or the extent of lateral neocortical resection (for all, $p>0.05$ ).

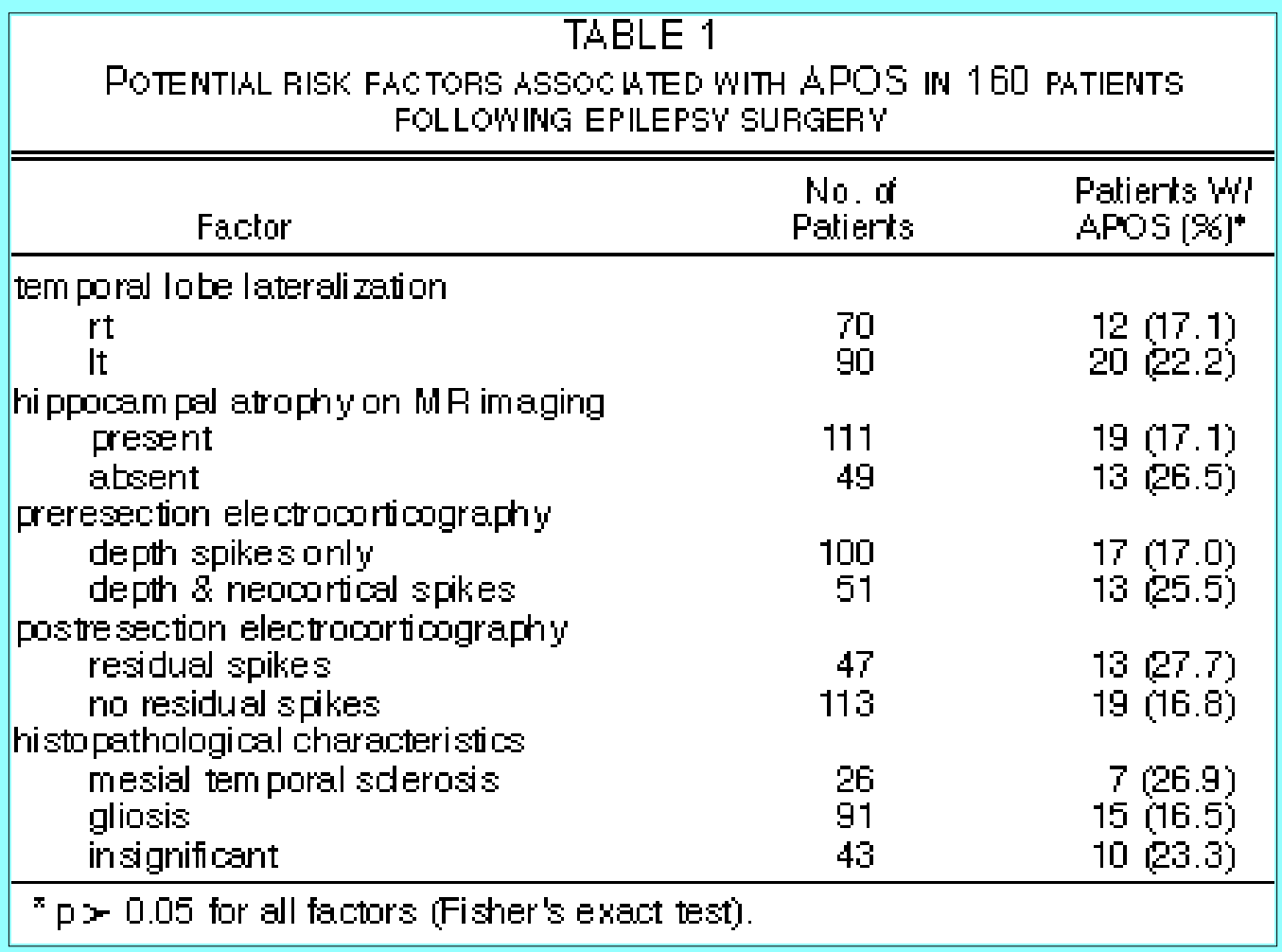

Hippocampal volume measurements were available in $143(89.4 \%)$ of the 160 patients. There was no significant difference between patients who had APOS and those who did not with respect to ipsilateral 
hippocampal volume ( $1.6 \mathrm{~mm}^{3}$ compared with $\left.1.5 \mathrm{~mm}^{3}, \mathrm{p}>0.05\right)$, contralateral hippocampal volume (2 $\mathrm{mm}^{3}$ compared with $2.1 \mathrm{~mm}^{3}, \mathrm{p}>0.05$ ), or side-to-side ratio ( 0.73 compared with $0.75, \mathrm{p}>0.05$ ).

At least one postoperative risk factor was identified in six of the patients with APOS. Five of these six patients had subtherapeutic antiepileptic drug levels and the remaining patient had meningitis. In addition to subtherapeutic antiepileptic drug levels, one patient had mild metabolic acidosis. No other perioperative complications were identified in patients with APOS.

\section{Outcome With Respect to Seizures}

A comparison of outcomes with respect to seizures in all patients who either had or did not have APOS is shown in Table 2. At the last follow-up examination, patients with APOS had a significantly lower rate of favorable long-term outcome. Patients with APOS had a significantly lower rate of excellent outcome at 1-year follow-up examination but not at their last follow-up examination.

\begin{tabular}{|c|c|c|c|}
\hline COMPARISON & $\begin{array}{r}\text { TABL } \\
\text { POSTSURGGAL } \\
\text { AND WITHOU }\end{array}$ & COMES IN PATIE & TS WITH \\
\hline $\begin{array}{c}\text { Postop } \\
\text { Outcome }\end{array}$ & $\begin{array}{c}\text { Patients } \\
\text { Wi APOS } \\
\text { [32 pati ents] }\end{array}$ & $\begin{array}{c}\text { Patients } \\
\text { W1O APOS } \\
\text { [128 patients] }\end{array}$ & $p$ Valuef \\
\hline $\begin{array}{l}3 \text { mos } \\
\text { excellent } \\
\text { faworable }\end{array}$ & $\begin{array}{l}23(71.9 \%) \\
27(84.4 \%)\end{array}$ & $\begin{array}{l}109(85.2 \%) \\
116(90.6 \%)\end{array}$ & $\begin{array}{l}0.11 \\
0.33\end{array}$ \\
\hline $\begin{array}{l}1 \text { yr } \\
\text { exoellent } \\
\text { faworatle } \\
\text { last followup }\end{array}$ & $\begin{array}{l}19(59.4 \%) \\
22(68.8 \%)\end{array}$ & $\begin{array}{r}99(77.3 \%) \\
107(83.6 \%)\end{array}$ & $\begin{array}{r}\times 0.05 \\
0.08\end{array}$ \\
\hline $\begin{array}{l}\text { excellent } \\
\text { faworable }\end{array}$ & $\begin{array}{l}20(62.5 \%) \\
20(62.5 \%)\end{array}$ & $\begin{array}{r}96(75.0 \%) \\
107(83.6 \%)\end{array}$ & $\begin{array}{r}0.19 \\
\times \quad 0.05 \\
\end{array}$ \\
\hline
\end{tabular}

Table 3 displays a comparison between outcomes with respect to seizures according to the types of APOS. Patients whose APOS were the same as their preoperative habitual seizures had a significantly worse outcome both at 1 year and at the last follow-up examination than patients whose APOS were typical of their preoperative auras or were FMS and/or GTCS only. 


\begin{tabular}{|ccc|}
\hline \multicolumn{5}{|c|}{ TABLE 3 } \\
COMPARISON OF POSTSURGCAL OUTCOMES ACCORD NG \\
TO TVPE OF APOS*
\end{tabular}

When compared with patients who did not have any APOS, the patients in the habitual seizure group had significantly worse outcomes at both 1 year and last follow up, whereas outcomes in patients who had auras only or only FMS or GTCS were not significantly different. There was no significant difference in outcome between early and late APOS (Table 4) or between patients with and patients without precipitating factors identified for their APOS (Table 5).

\begin{tabular}{|c|c|c|c|}
\hline COMPARISON & $\begin{array}{r}\text { TABL } \\
\text { OSTSURGKAL } \\
\text { LATE A } \\
\end{array}$ & MES BETWEEN & $Y$ AND \\
\hline Postop Outcome & $\begin{array}{l}\text { Patients Wl } \\
\text { Early APOS } \\
\text { (15 patients) }\end{array}$ & $\begin{array}{l}\text { Patierts WI } \\
\text { Late APOS } \\
\text { [17 pati ents] }\end{array}$ & $p$ Valuet \\
\hline $3 \mathrm{mos}$ & & & \\
\hline excellent & $12(80 \%)$ & $11(64.7 \%)$ & 0.44 \\
\hline $\begin{array}{l}\text { faworable } \\
1 \mathrm{w}\end{array}$ & $13(86.7 \%)$ & $14(82.4 \%)$ & \\
\hline exoellent & $9(60 \%)$ & $10(58.9 \%)$ & 1.0 \\
\hline $\begin{array}{c}\text { faworabte } \\
\text { last followion }\end{array}$ & $11(73.3 \%)$ & $11(64.7 \%)$ & 0.71 \\
\hline $\begin{array}{l}\text { last rollow up } \\
\text { exoellent }\end{array}$ & $10(66.7 \%)$ & $10(58.9 \%)$ & 0.73 \\
\hline faworable & $10(66.7 \%$ & $10(58.9 \%)$ & 0.73 \\
\hline $\begin{array}{l}\text { "Early AP CS = } \\
\text { exoellent outtom } \\
\text { ified Engel Cass } \\
\text { ring after the firs } \\
\dagger \text { Fisher's exac }\end{array}$ & $\begin{array}{l}\text { derati ie sei } \\
\text { dified Enge } \\
\text { d II; late AP } \\
\text { drs. }\end{array}$ & $\begin{array}{l}\text { nfined to th } \\
\text { i faworable } \\
\text { osto perative }\end{array}$ & $\begin{array}{l}4 \text { hours } \\
=\text { mod- } \\
\text { s ocour- }\end{array}$ \\
\hline
\end{tabular}




\begin{tabular}{|c|c|c|c|}
\hline $\begin{array}{r}\text { COMPARISON } \\
\text { FR }\end{array}$ & $\begin{array}{l}\text { TABL } \\
\text { POSTSURGICAL } \\
\text { APOS BV THE } \\
\text { FACTORS PRECIF }\end{array}$ & $\begin{array}{l}\text { OMES IN PATIENT } \\
\text { ENCE OR ABSEN } \\
\text { ING SEIZURES }\end{array}$ & FER NG \\
\hline Postop Outcome & $\begin{array}{l}\text { Precipitating } \\
\text { Factors Presert } \\
\text { (6 patients] }\end{array}$ & $\begin{array}{l}\text { Precipitating } \\
\text { Factors Abserk } \\
\text { (26 pa.b ents) }\end{array}$ & $\mathrm{p}$ Valu e† \\
\hline $3 \mathrm{mos}$ & & & \\
\hline $\begin{array}{l}\text { excellent } \\
\text { favorable }\end{array}$ & $\begin{array}{l}4(66.7 \%) \\
5(83.3 \%)\end{array}$ & $\begin{array}{l}19(73.1 \%) \\
22(84.6 \%)\end{array}$ & $\begin{array}{l}1.0 \\
1.0\end{array}$ \\
\hline $\begin{array}{l}1 \text { yr } \\
\text { exoellent } \\
\text { faworable } \\
\text { last follow up }\end{array}$ & $\begin{array}{l}2(33.3 \%) \\
3(50.0 \%)\end{array}$ & $\begin{array}{l}17(65.4 \%) \\
19(73.1 \%)\end{array}$ & $\begin{array}{l}0.19 \\
0.34\end{array}$ \\
\hline $\begin{array}{l}\text { excellent } \\
\text { fawora.ble }\end{array}$ & $\begin{array}{l}3(50.0 \%) \\
3(50.0 \%)\end{array}$ & $\begin{array}{l}17(65.4 \%) \\
20(76.9 \%)\end{array}$ & $\begin{array}{l}0.65 \\
0.31\end{array}$ \\
\hline $\begin{array}{l}\text { * Excellent ou } \\
\text { modified Engel } \\
\dagger \text { Fisher's exac }\end{array}$ & $\begin{array}{l}\text { = modified } \\
\text { es I and II. }\end{array}$ & Cass I; fan & outct \\
\hline
\end{tabular}

\section{DISCUSSION}

Anterior temporal lobectomy for intractable nonlesional temporal lobe epilepsy is the most common type of epilepsy surgery. Overall, 20 to $40 \%$ of patients who undergo ATL have seizure recurrence after surgery. $[4,10,26,29,32]$ In these patients the seizures usually first recur within 6 to 12 months after surgery and many persist afterward.[1,11,21,25,29,32] In most previous studies of outcome following epilepsy surgery, the early postoperative seizures that occurred during the hospital stay have been ignored and, consequently, there is little information currently available regarding the incidence and prognostic significance of APOS.[24] In this study we have demonstrated that APOS are not an infrequent occurrence after an ATL, with $20 \%$ of our patients experiencing at least one seizure in the 1 st postoperative week. Wingkun, et al.,[32] identified 72 patients who had recurrent postoperative seizures after resective epilepsy surgery (both temporal and extratemporal), of whom $29 \%$ had their first seizure in the 1st postoperative week. These authors reported that the long-term prognosis in these patients was not significantly different from those in whom the first postoperative seizure occurred later in the $1 \mathrm{st}$ year. However, these authors did not report on the overall incidence of APOS in their patients who underwent epilepsy surgery nor did they compare outcomes in patients who had APOS with those who did not have APOS. Bengzon and colleagues[3] found that a higher proportion of patients who had poor long-term outcomes after ATL experienced in-hospital postoperative seizures compared with patients who had good long-term outcomes. However, these authors also did not report the incidence or prognostic significance of APOS occurring in a consecutive series of patients. Garcia, et al.,[17] published the only previous study of APOS in a consecutive group of patients who underwent temporal lobectomy; these authors found that seizures occurred during the 1st postoperative week in 27 (49\%) of 55 patients and that these patients were significantly less likely to experience long-term seizure-free outcomes than those who did not have postoperative seizures.

In contrast, other authors have stated that seizures that occur during the early postoperative period are not necessarily associated with poor long-term outcome. $[9,11,24,26]$ It has been suggested that these seizures, which are often FMS or GTCS, may result from the effects of acute surgical injury and they have been termed neighborhood seizures.[3,10,11,24,26] In a series of 100 consecutive patients who underwent ATL, Falconer and Serafetinides[11] reported that 45 patients had transient neighborhood 
seizures during the first 2 weeks after surgery. These authors were of the opinion that, similar to acute posttraumatic seizures, "neighborhood" seizures do not necessarily incur a bad prognosis.

The findings of our study support the conclusion that full seizure control in the 1st week portends a favorable long-term outcome (Table 2). Overall, patients with APOS were found to have less likelihood of favorable outcome at their last follow-up examination than patients without APOS. However, the majority of our patients with APOS still had a favorable outcome (62.5\%). There was no overall difference between the two groups in the proportion of patients with excellent outcome.

Many previous authors have believed that the type of APOS may have prognostic importance, with patients who have FMS or GTCS having a better long-term prognosis than those who have habitual complex partial seizures.[3,10,24,26,32] However, Garcia, et al.,[17] found no difference in long-term outcomes between patients with postoperative seizures that were similar to preoperative seizures and those with seizures different from preoperative seizures. The results of our study, in contrast, strongly support the conclusion that the type of APOS is of prognostic importance. We found that patients who had APOS that were similar to their habitual preoperative seizures had a significantly lower rate of either excellent or favorable outcome at last follow-up examination than patients whose APOS were their typical auras, FMS, or GTCS. In fact, outcome in patients with only auras or with only FMS or GTCS was not significantly different from that in patients without APOS. The prognostic implications of the type of APOS that have been demonstrated in this study are of major importance in counseling patients. The most likely explanation for these findings is that recurrence of habitual seizures in the postoperative period indicates that the epileptogenic zone has not been adequately resected.[26,32] Conversely, APOS that are different in nature from the preoperative habitual seizures may be induced by an acute disruption of the normal cerebral physiology and anatomy by the surgical procedure without the establishment of a long-term epileptogenic focus. $[8,10,23]$ This is supported by the fact that APOS, particularly GTCS and FMS, not uncommonly occur following otherwise uncomplicated general neurosurgical craniotomies, with a reported incidence of 1 to $27 \%$, depending on the nature of the surgery and the underlying pathological condition.[2,7,12,13,20,23,28] However, in these patients the APOS do not appear to be associated with an increased long-term likelihood of developing epilepsy.[2,12,20,28]

It is of interest that the recurrence of isolated auras in the immediate postoperative period was not associated with a decreased chance for either an excellent or favorable long-term outcome with respect to seizures. It is now well recognized that, despite successful ATL resulting in long-term freedom from consciousness-impairing seizures, auras still persist in up to $35 \%$ of patients.[14,15,22,30] In addition, it has been demonstrated that activity seen on intracranial electroencephalography may differ between the independent auras and the onset of complex partial seizures in many patients with temporal lobe epilepsy, but this does not affect outcome following temporal lobectomy.[30,31] These findings have led to the suggestion that there may be an anatomical and pathophysiological dissociation between the cerebral generators of auras and of consciousness-impairing seizures in these patients.[14,15,30] The results of our current study lend further support to this hypothesis.

Antiepileptic drug levels are known to decline during the early postoperative period.[16] Many investigators thought that APOS that were provoked by inadequate anticonvulsant prophylaxis did not carry a poor prognosis. $[1,10,17,24]$ It has also been suggested that seizures precipitated by metabolic disturbances, such as electrolyte imbalance, hypoxia, hypoglycemia, or hypocapnia, also have no prognostic value.[1,10,24] In our study, six $(18.8 \%)$ of the 32 patients with APOS had either subtherapeutic antiepileptic drug levels or other potentially precipitating factors. We did not find any 
significant difference in long-term outcomes between patients with and patients without precipitating factors (Table 5). It has also been suggested that APOS that are confined to the first 24 hours after surgery may be less prognostically important because this is when the acute surgical effects are the most pronounced and the risk of a low antiepileptic drug level is greatest.[17,24] The results of our study, however, do not support this opinion because we found no significant difference in long-term outcomes between early and late APOS.

There are few data in the literature about preoperative or intraoperative factors that predict which patients are at risk for APOS. We were unable to find any factor that increased the risk of APOS. There was a trend for patients with residual spiking on postresection electrocorticography to experience APOS; however, this trend did not attain statistical significance $(27.7 \%$ compared with $16.8 \% ; \mathrm{p}=0.13)$. This finding extends the results of a number of previous studies, including one from our center, that findings on postresection electrocorticography do not significantly correlate with long-term postoperative seizure control.[26,27,29,33] In this study, we had hypothesized that patients who had symmetrical hippocampal volumes have a higher risk of APOS. However, the hypothesis was not supported by our findings.

\section{CONCLUSIONS}

In this study we found that the occurrence of APOS following ATL for nonlesional temporal lobe epilepsy was associated with a somewhat worse prognosis for long-term seizure control, but this was confined to patients who had seizures that were similar to their preoperative habitual seizures. Patients whose APOS were only auras or either FMS or GTCS had a long-term prognosis similar to those who did not have APOS. Timing of the APOS and identification of a potential precipitating factor were not found to be of prognostic importance. The findings of this study should prove useful in counseling patients who suffer from APOS following ATL for nonlesional temporal lobe epilepsy.

\section{References}

1. Awad IA, Nayel MH, Luders H: Second operation after the failure of previous resection for epilepsy. Neurosurgery 28:510-518, 1991

2. Baker CJ, Prestigiacomo CJ, Solomon RA: Short-term perioperative anticonvulsant prophylaxis for the surgical treatment of low-risk patients with intracranial aneurysms. Neurosurgery 37:863-871, 1995

3. Bengzon ARA, Rasmussen T, Gloor P, et al: Prognostic factors in the surgical treatment of temporal lobe epileptics. Neurology 18:717-731, 1968

4. Berkovic SF, McIntosh AM, Kalnins RM, et al: Preoperative MRI predicts outcome of temporal lobectomy: an actuarial analysis. Neurology 45:1358-1363, 1995

5. Cascino GD, Jack CR Jr, Parisi JE, et al: Magnetic resonance imaging-based volume studies in temporal lobe epilepsy: pathological correlations. Ann Neurol 30:31-36, 1991

6. Cascino GD, Trenerry MR, Jack CR Jr, et al: Electrocorticography and temporal lobe epilepsy: relationship to quantitative MRI and operative outcome. Epilepsia 36:692-696, 1995

7. De Santis A, Baratta P, Bello L, et al: Early postoperative seizures and endovenous phenytoin. Preliminary clinical data. J Neurosurg Sci 40:207-212, 1996 
8. Deutschman CS, Haines SJ: Anticonvulsant prophylaxis in neurological surgery. Neurosurgery 17:510-517, 1985

9. Engel J Jr: Outcome with respect to epileptic seizures, in Engel J Jr (ed): Surgical Treatment of the Epilepsies. New York: Raven Press, 1987, pp 553-571

10. Engel J Jr, Van Ness PC, Rasmussen TB, et al: Outcome with respect to epileptic seizures, in Engel J Jr (ed): Surgical Treatment of the Epilepsies, ed 2. New York: Raven Press, 1993, pp 609-621

11. Falconer MA, Serafetinides EA: A follow-up study of surgery in temporal lobe epilepsy. J Neurol Neurosurg Psychiatry 26:154-165, 1963

12. Foy PM, Chadwick DW, Rajgopalan N, et al: Do prophylactic anticonvulsant drugs alter the pattern of seizures after craniotomy? J Neurol Neurosurg Psychiatry 55:753-757, 1992

13. Foy PM, Copeland GP, Shaw MDM: The natural history of postoperative seizures. Acta Neurochir 57:15-22, 1981

14. Fried I: Auras and experiential responses arising in the temporal lobe. J Neuropsychiatr Clin Neurosci 9:420-428, 1997

15. Fried I, Spencer DD, Spencer SS: The anatomy of epileptic auras: focal pathology and surgical outcome. J Neurosurg 83:60-66, 1995

16. Friel P, Clarke H, Ojemann G, et al: Decreased serum anticonvulsant levels after epilepsy surgery. Epilepsia 28 (Suppl):588, 1987 (Abstract)

17. Garcia PA, Barbaro NM, Laxer KD: The prognostic value of postoperative seizures following epilepsy surgery. Neurology 41:1511-1512, 1991

18. Jack CR Jr, Sharbrough FW, Twomey CK, et al: Temporal lobe seizures: lateralization with MR volume measurements of the hippocampal formation. Radiology 175:423-429, 1990

19. Jack CR Jr: Magnetic resonance imaging. Neuroimaging and anatomy. Neuroimaging Clin North Am 5:597-622, 1995

20. Kvam DA, Loftus CM, Copeland B, et al: Seizures during the immediate postoperative period. Neurosurgery 12:14-17, 1983

21. Lüders H, Murphy D, Dinner D, et al: Prognostic value of epileptic seizures occurring in the first week after surgery of epilepsy. Epilepsia 29 (Suppl):679, 1988 (Abstract)

22. Lund JS, Spencer SS: An examination of persistent auras in surgically treated epilepsy. Epilepsia 33 (Suppl):95, 1992 (Abstract)

23. Matthew E, Sherwin AL, Welner SA, et al: Seizures following intracranial surgery: incidence in the first post-operative week. Can J Neurol Sci 17:285-289, 1980

24. Ojemann GA, Bourgeosis BF: Early postoperative management, in Engel J Jr (ed): Surgical Treatment of the Epilepsies, ed 2. New York: Raven Press, 1993, pp 539-540

25. Penfield W, Paine K: Results of surgical therapy for focal epileptic seizures. Can Med Assoc J 
73:515-530, 1955

26. Primrose DC, Ojemann GA: Outcome of resective surgery for temporal lobe epilepsy, in Lüders $H$ (ed): Epilepsy Surgery. New York: Raven Press, 1991, pp 601-611

27. Rasmussen TB: Surgical treatment of complex partial seizures: results, lessons, and problems. Epilepsia 24 (Suppl 1):S65-S76, 1983

28. Shaw MDM: Post-operative epilepsy and the efficacy of anticonvulsant therapy. Acta Neurochir Suppl 50:55-57, 1990

29. So EL, Radhakrishnan K, Silbert PL, et al: Assessing changes over time in temporal lobectomy: outcome by scoring seizure frequency. Epilepsy Res 27:119-125, 1997

30. Sperling MR, Lieb JP, Engel J Jr, et al: Prognostic significance of independent auras in temporal lobe seizures. Epilepsia 30:322-331, 1989

31. Sperling MR, O'Connor MJ: Auras and subclinical seizures: characteristics and prognostic significance. Ann Neurol 28:320-328, 1990

32. Wingkun EC, Awad IA, Lüders H, et al: Natural history of recurrent seizures after resective surgery for epilepsy. Epilepsia 32:851-856, 1991

33. Wyllie E, Lüders H, Morris HH III, et al: Clinical outcome after complete or partial cortical resection for intractable epilepsy. Neurology 37:1634-1641, 1987

Manuscript received November 26, 1997.

Accepted in final form March 24, 1998.

Address for Drs. Malla and Radhakrishman: Sree Chitra Tirunal Institute for Medical Sciences and Technology, Thiruvananthapuram, India.

Address for Dr. O'Brien: The Australian Centre for Clinical Neuropharmacology, and the Comprehensive Epilepsy Programs of St. Vincent's and The Royal Melbourne Hospitals, Victoria, Australia.

Address for Dr. Silbert: The Royal Perth Hospital, Perth, Western Australia, Australia.

Address reprint requests to: Gregory D. Cascino, M.D., Department of Neurology, Mayo Clinic, 200 First Street S.W., Rochester, Minnesota 55905. email: gcascino@ mayo.edu. 